\title{
MicroRNA-125b-1-3p mediates intervertebral disc degeneration in rats by targeting teashirt zinc finger homeobox 3
}

\author{
XIAOTONG MENG, YUE ZHU, LIN TAO, SICHAO ZHAO and SHUI QIU \\ Department of Orthopedics, The First Affiliated Hospital of China Medical University, Shenyang, Liaoning 110001, P.R. China
}

Received July 13, 2017; Accepted November 17, 2017

DOI: 10.3892/etm.2018.5715

\begin{abstract}
The present study aimed to investigate the association between Teashirt zinc finger homeobox 3 (TSHZ3) and the nucleus pulposus (NP) of intervertebral discs in rats. TSHZ3 was identified from the differentially expressed micro (mi) RNAs in the expression profile of GSE63492 by identifying the overlapped target genes of microRNA (miR)-125b-1-3p across different databases. TSHZ3 small interfering RNA (siRNA) and an miR-125b-1-3p inhibitor were used for gene silencing and gene silencing efficiency was assessed by reverse transcription-polymerase chain reaction. Western blotting was performed to detect the cell cycle proteins cyclin D1 and B1 and the proteins associated with DNA damage in NP. The results revealed that in normal NPs, the expression of TSHZ3 increased following the inhibition of miR-125b-1-3p and in DNA damaged NPs, the expression of TSHZ3 was associated with the degree of DNA damage. The present study demonstrated that TSHZ3, as a target gene of miR-125b-1-3p, may serve a protective role in intervertebral disc degeneration and that this protective function may be inhibited by high levels of miR-125b-1-3p.
\end{abstract}

\section{Introduction}

Lumbar disc herniation is a common disease that initially manifests as lumbar back pain. It subsequently shifts to the hips and lower limbs and may cause severe dysfunction of the lower limbs and paralysis. The effects of the disease may therefore cause a considerable economic burden on society $(1,2)$. It has been suggested that the gradual degeneration of the intervertebral disc may be responsible $(3,4)$. This initially occurs in the nucleus pulposus (NP) and involves the loss of existing cells and changes of the extracellular matrix (5). The outer layer of the fibrous ring may change its normal lamellar

Correspondence to: Dr Yue Zhu, Department of Orthopedics, The First Affiliated Hospital of China Medical University, 155 Nan Jing Bei Street, Shenyang, Liaoning 110001, P.R. China

E-mail: zhuyuedr@163.com

Key words: intervertebral disc degeneration, cell proliferation, DNA damage, microRNAs arrangement, progressively, cracks may begin to gradually emerge from the inner part of the fiber ring to the outside, leading to a change in the overall mechanics of the lumbar disk (6). These changes increase the force that passes to the end of the vertebral body resulting in minor fractures and marginal osteophyte formation (7). Certain environmental factors, including weightlifting, vibration massage, trauma, smoking, diabetes, cerebrovascular disease and infections may induce mechanical stress or alter the metabolism of the intervertebral disc (8). Therefore, intervertebral disc degeneration is a result of long-term effects by multiple damaging factors and further research is required to fully understand the potential causes and its molecular mechanisms of action.

Microarrays are high-throughput platforms used to analyze gene expression, which may be used to examine a broad range of signaling pathways and have a high degree of reliability (9-11). In the present study the downregulated miRNA miR-125b-1-3p was investigated. Follow-up experiments were performed to assess the target genes of miR3150A.

The microRNA miR-125b-1-3p has diverse functions, including in development, differentiation, cell proliferation and apoptosis $(12,13)$. Previous research has implied that it may serve as a tumor suppressor or an oncogene (14); it is downregulated in malignancies originating in the ovaries, bladder and breast, but upregulated in leukemia, prostate cancer and glioma (15). At present the exact influence of miR-125b-1-3p on NP cells remains unclear.

Homeobox genes serve key roles in the standardization and patterning development in different parts of the body $(16,17)$. The human genome contains at $\geq 178$ homeobox sequences, among which 160 genes may be translated into homeodomains within functional proteins (18). Teashirt zinc finger homeobox 3 (TSHZ3) encodes a zinc-finger transcription factor and is highly expressed in the developing human neocortex (19). TSHZ3 also serves a primary role in smooth muscle formation (20) but its specific functions remain ambiguous. The present study aimed to determine whether TSHZ3 is a direct target of miR-125b-1-3p. Furthermore, the potential association between miR-125b-1-3p, TSHZ3 and the degeneration of rat NP cells was investigated.

\section{Materials and methods}

Microarray data. In the present study, the gene expression profile GSE63492 was downloaded from the GEO database. 

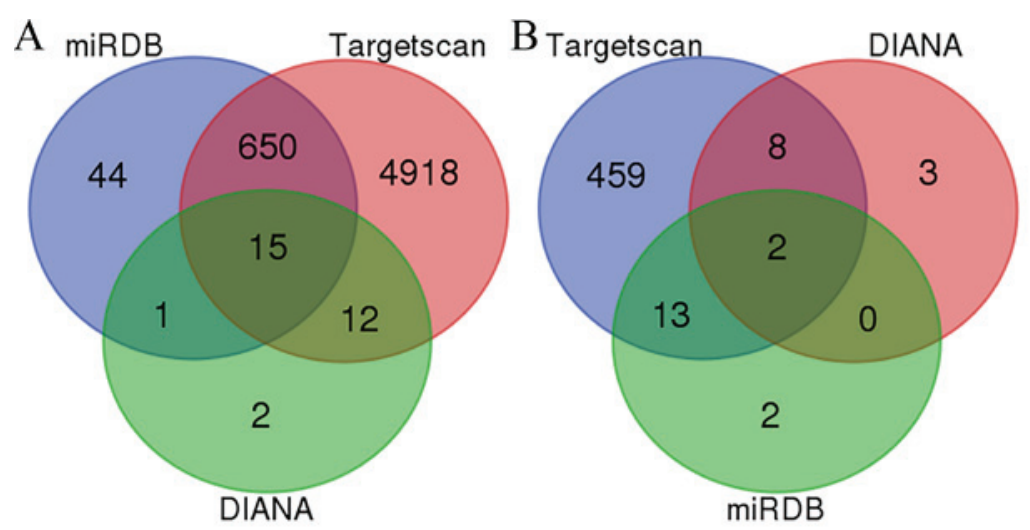

Figure 1. Venn map of the overlapping miRNAs from different databases (Targetscan, miRDB and DIANA). (A) Overlapped upregulated miRNAs; (B) overlapped downregulated miRNAs. miR, microRNA.

GSE63492 was based on an Agilent GPL19449 platform which entitled: Exiqon miRCURY LNA microRNA Array, 7th generation REV-hsa, mmu \& rno (miRBase v18.0), submitted by Liu et al (21). The GSE63492 dataset contained 10 samples in total, 5 of which were samples from patients with IDD and the other 5 were tissues from individuals with normal discs. A total of 134 micro (mi)RNAs (DEMs) have been identified as differentially expressed in intervertebral disc degeneration (IDD) by gene expression profiling studies using microarray technology (22). MicroRNA (miR)3150A was selected from the upregulated miRNAs and miR-125b-1-3p was selected from the downregulated miRNAs as these were identified as the most significant. Their target genes were predicted by finding overlapping genes across different databases (Targetscan, http://www.targetscan. org/; miRDB, http://mirdb.org/ and DIANA, http://diana.imis. athena-innovation.gr/). It was observed that miR3150A had 15 overlapping genes, whereas miR-125b-1-3p had only two: GLRA2 and TSHZ3 (Fig. 1). The follow-up experiments were performed to assess the target genes of miR3150A.

Cell culture and reagents. A total of 20 male Sprague Dawley rats ( 8 weeks old, $150 \pm 20 \mathrm{~g}$ ) were obtained from Tongji University (Shanghai, China). Rats were maintained in a room with a 12 -h light/dark cycle (temperature, $18-26^{\circ} \mathrm{C}$; humidity, $40-70 \%$ ) and had free access to food (5 $\mathrm{g}$ for $100 \mathrm{~g}$ weight $/ 24 \mathrm{~h}$ ) and drinking water $(8-11 \mathrm{ml}$ for $100 \mathrm{~g}$ weight $/ 24 \mathrm{~h}$ ). Rats were euthanized prior to the isolation of NP on a super-clean bench. NP tissues were minced to $1 \mathrm{~mm}^{3}$ and digested with trypsin for $25 \mathrm{~min}$ at $37^{\circ} \mathrm{C}$. Tissues were washed three times using phosphate buffered solution (PBS) following centrifugation at $240 \mathrm{x} \mathrm{g}$ for $10 \mathrm{~min}$ at room temperature and added to Dulbecco's Modified Eagle's medium (DMEM) F-12 (HyClone, Laboratories; GE Healthcare Life Sciences, Logan, UT, USA) containing 15\% fetal bovine serum (FBS) (Clark Bioscience, Richmond, VA, USA) and $0.25 \%$ collagenase type II (COL2; Sigma-Aldrich; Merck KGaA, Darmstadt, Germany) for $3 \mathrm{~h}$ at $37^{\circ} \mathrm{C}$. The tissues digested by collagenase type II were finally isolated in $15 \%$ FBS following three washes using phosphate buffered solution (PBS) and centrifuged at $170 \mathrm{xg}$ for $5 \mathrm{~min}$ at room temperature. The NP cells were adherent and then cultured in DMEM F-12 with $15 \%$ FBS (replaced every 3 days) in $5 \% \mathrm{CO}_{2}$ at $37^{\circ} \mathrm{C}$. When the primary cells formed a monolayer, they were digested by trypsin and passaged to the third and fifth generation for the follow-up experiment.

The present study was performed according to international, national and institutional rules concerning animal experiments, clinical studies and biodiversity rights. The study protocol was approved by the Laboratory Animal Welfare and Ethical Committee of Shanghai Tenth People's Hospital affiliated to Tongji University (Shanghai, China).

MiR-125b-1-3p inhibitor and TSHZ3 small interfering (si)RNA transfection. Cells were cultured in DMEM with F12 supplemented with $10 \%$ FBS in a humidified incubator at $5 \% \mathrm{CO}_{2}$ and $37^{\circ} \mathrm{C}$. When they reached $70-80 \%$ confluence, cells were transfected with Lipofectamine $2000^{\circledR}$ (Invitrogen; Thermo Fisher Scientific, Inc., Waltham, MA, USA) and either miR-125b-1-3p inhibitor (Shanghai GeneChem Co., Ltd., Shanghai, China) or TSHZ3 siRNA (Genechem), following the manufacturer's protocol.

Luciferase assay. The wild type or mutant TSHZ3 3'-untranslated region (UTR; Shanghai GeneChem Co., Ltd.) was cloned into the pmirGLO luciferase reporter vector (Promega Corporation, Madison, WI, USA) and co-transfected using Lipofectamine 2000 (Invitrogen; Thermo Fisher Scientific, Inc.) with either the miR-590-3p mimic or the miR-negative control (NC; Shanghai GeneChem Co., Ltd.) into 293T cells using Lipofectamine $2000^{\circledR}$. The pRL-TK Renilla luciferase reporter vector (Promega Corp., Madison, WI, USA) was transfected into cells as an internal control. At $24 \mathrm{~h}$ post-transfection, luciferase activity was measured using a Dual-Luciferase ${ }^{\circledR}$ Reporter assay system (Promega Corp.), following cell lysis with passive lysis buffer included in the Reporter assay system. Relative luciferase activity was calculated as the ratio of firefly luciferase activity to Renilla luciferase activity.

Western blot analysis. NP cells were treated with different concentrations of $\mathrm{H}_{2} \mathrm{O}_{2}(0.05,0.1$ and $0.2 \mathrm{mM} / \mathrm{l})$ to simulate DNA oxidative damage. Cells were collected at $0,0.5,1$ and $2 \mathrm{~h}$ following administration of $\mathrm{H}_{2} \mathrm{O}_{2}$. Total proteins were extracted from the NP cells using radioimmunoprecipitation assay lysis buffer (Beyotime Institute of Biotechnology, Shanghai, China) for $30 \mathrm{~min}$ at $4^{\circ} \mathrm{C}$. The supernatant containing total protein was harvested and proteins were 
A

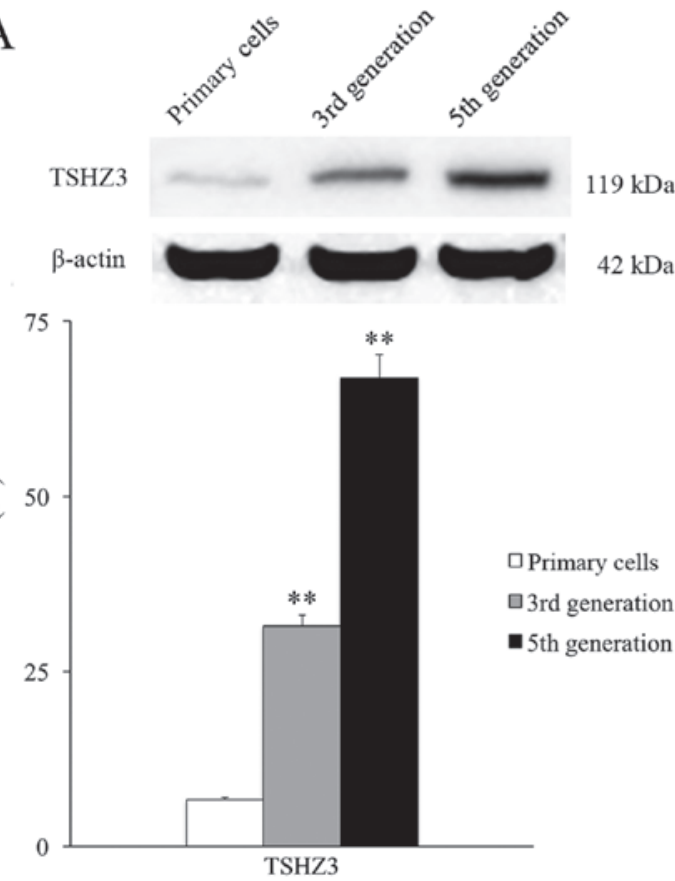

B

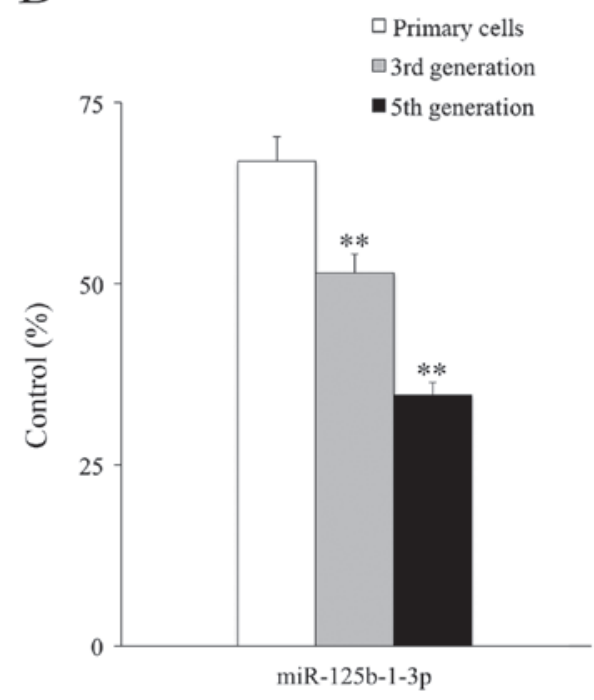

Figure 2. Expression of TSHZ3 and miR-125b-1-3p in NP cells. (A) The expression of TSHZ3 in NP cells from different generations. (B) The expression of miR-125b-1-3p in NP cells from different generations. ${ }^{* *} \mathrm{P}<0.01$ vs. primary cells. NP, nucleus pulposus; TSHZ3, Teashirt zinc finger homeobox 3 ; miR, microRNA.

quantified using the bicinchoninic acid method. Aliquots containing $50 \mu \mathrm{g}$ protein were separated by $12 \%$ SDS-PAGE and transferred to polyvinylidene difluoride membranes at $60 \mathrm{~V}$ for $2 \mathrm{~h}$ at $4^{\circ} \mathrm{C}$. Membranes were then soaked in $5 \%$ blocking buffer, containing $25 \mathrm{mg}$ bovine serum albumin (Beyotime Institute of Biotechnology) in Tris buffered saline (TBS) buffer to final volume of 0.51 , at $4^{\circ} \mathrm{C}$ for $2 \mathrm{~h}$ and subsequently incubated with primary antibodies against TSHZ3 (cat. no. ab176117; ), COL2 (cat. no. ab34712), cyclin D1 (cat. no. ab134175), cyclin B1 (cat. no. ab2949; all Abcam, Cambridge, MA, USA) at 1:5,000 dilution overnight at $4^{\circ} \mathrm{C}$. This was followed by incubation with goat anti-rabbit peroxidase-conjugated secondary antibodies (cat. no. ab6721; Abcam) at 1:10,000 dilution for $2 \mathrm{~h}$ at room temperature. The DNR imaging system (DNR Bio-Imaging Systems, Ltd., Jerusalem, Israel) was used to visualize specific bands, and the optical density of each band was measured using ImageJ software (version 1.51; NIH, Bethesda, MD, USA). The ratio between the target proteins and $\beta$-actin was calculated and presented graphically.

Reverse transcription-quantitative polymerase chain reaction $(R T-q P C R)$ assay. Total RNA was extracted from NP cells using the E.Z.N.A. ${ }^{\circledR}$ Total RNA Midi kit (Omega Bio-Tek, Inc., Norcross, GA, USA) following the manufacturer's protocol and quantified spectrophotometrically at $260 \mathrm{~nm}$ with acceptable CCLX/280 ratios between 1.8 and 2.0. RNA quality was determined by $1 \%$ agarose gel electrophoresis and staining with $1 \mu \mathrm{g} / \mathrm{ml}$ ethidium bromide (room temperature, $5 \mathrm{~min}$ ). qPCR was performed on LightCycler ${ }^{\circledR} 480$ High-Resolution Melting Master (Roche Diagnostics, Basel, Switzerland) using SYBR Premix Ex Taq ${ }^{\mathrm{TM}}$ II (Takara Biotechnology Co., Ltd., Dalian, China). Specific primers for miR-125b-1-3p (forward primer, 5'ACGGGTTAGGCTCTTGG3'; and reverse primer, 5'CAGTGCGTGTCGTGGAGT3') and TSHZ3 (forward primer, 5'-GCAGCAGCCTATGTTTCCGATG-3'; and reverse primer, 5'-GTAGCTAGGGCAGGCTTTGC-3') were obtained from Shanghai GeneChem Co., Ltd. Amplifications were performed in a total reaction volume of $20 \mu \mathrm{l}$ and cycled 40 times following initial denaturation $\left(95^{\circ} \mathrm{C}\right.$ for $\left.30 \mathrm{sec}\right)$ using the following parameters: $95^{\circ} \mathrm{C}$ for $5 \mathrm{sec}$ and $60^{\circ} \mathrm{C}$ for $30 \mathrm{sec}$. $\beta$-actin (forward primer, TCCTCCCTGGAGAAGAGCTA, and reverse primer, TCAGGAGGAGCAATGATCTTG) were used as the internal controls. Analysis of the melting curve supported the reliability of the results. RT-qPCR data was quantified using the $2^{-\Delta \Delta \mathrm{Cq}}$ method (23).

Statistical analysis. SPSS 20.0 software (IBM Corp., Armonk, NY, USA) was used analyze the data. The one sample t-test was used to evaluate the differences among different generations under the same treatment factors. One-way analysis of variance which followed by the student Newman-Keuls test was used to evaluate the differences among different groups treated with different concentrations of $\mathrm{H}_{2} \mathrm{O}_{2}$ and times. All data are presented as the mean \pm standard error of the mean and a minimum of three independent repeats were performed for each experiment. $\mathrm{P}<0.05$ was considered to indicate a statistically significant difference. $\mathrm{N}$-fold values in gene expression $\leq 0.5$ and $>2$ were taken to be significant, in accordance with values obtained from control genes.

\section{Results}

The expression of TSHZ3 was assessed by extracting membrane proteins from normal rat NP cells at different passages (primary cells, the third-generation cells and the 

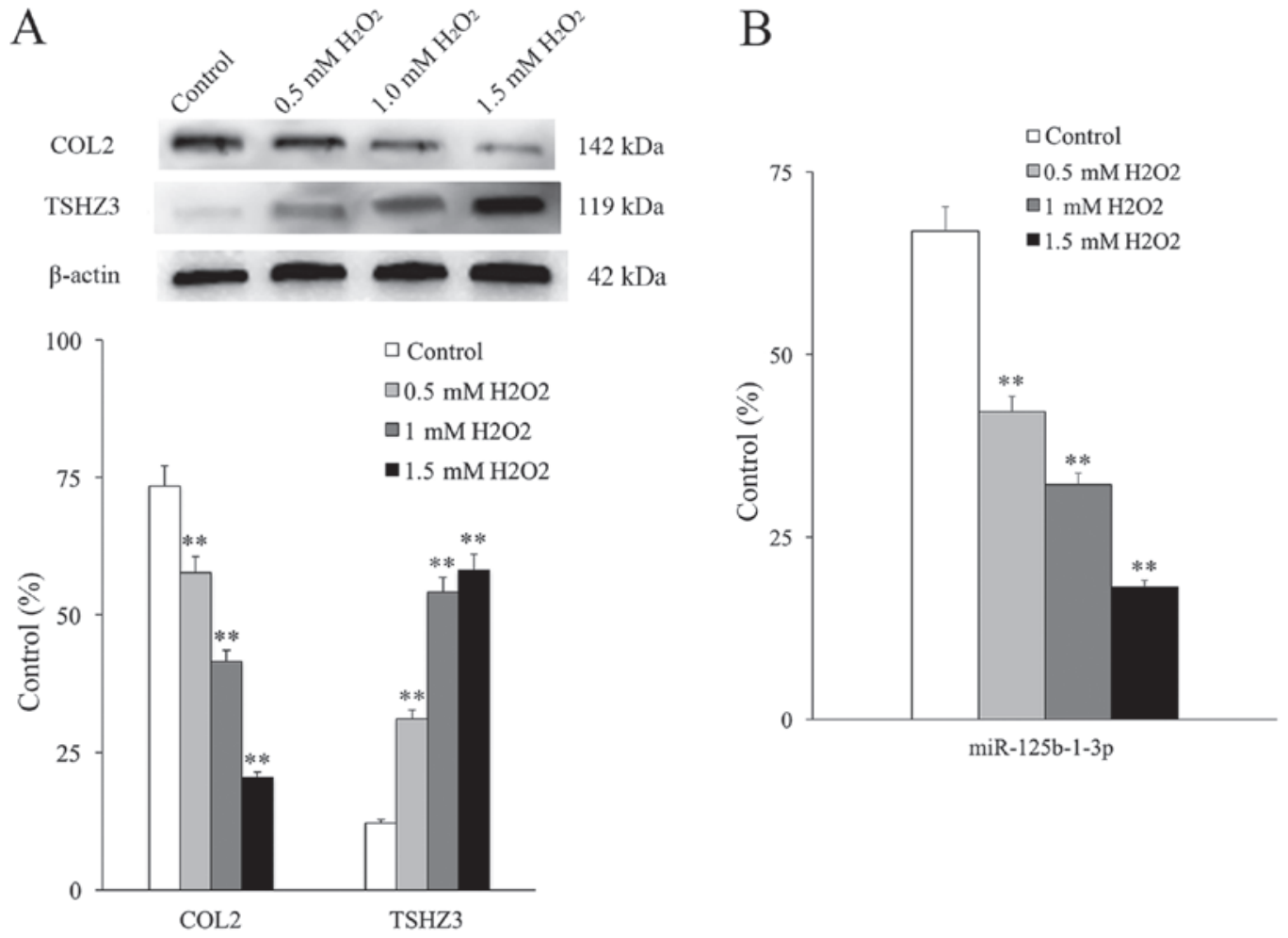

Figure 3. The effect of $\mathrm{H}_{2} \mathrm{O}_{2}$ administration on NP cells. (A) The expression of COL2 and TSHZ3 and (B) miR-125b-1-3p were determined in NP cells following treatment with $0.5,1.0$ and $1.5 \mathrm{mM} / 1 \mathrm{H}_{2} \mathrm{O}_{2}$ for $24 \mathrm{~h}$. ${ }^{* * *} \mathrm{P}<0.01$ vs. control cells. miR, microRNA. NP, nucleus pulposus; TSHZ3, Teashirt zinc finger homeobox 3; COL2, collagenase type II.

fifth-generation cells) and measuring the expression of TSHZ3 by western blotting. Expression of TSHZ3 was low in primary NP cells, however TSHZ3 expression exhibited a passage-dependent increase; third and fifth generation cells expressed TSHZ3 at a significantly higher level than the primary cells $(\mathrm{P}<0.01$; Fig. 2A). Expression levels of miR-125b-1-3p exhibited a passage-dependent change and there were significant differences observed between generations (Fig. 2B). When the NP cells were cultured in vitro to the third generation, degeneration was clear and mainly characterized by the markedly decreased expression level of COL2 (Fig. 3A).

It had been demonstrated that $\mathrm{H}_{2} \mathrm{O}_{2}$ may stimulate DNA oxidative damage in the NP cells of rats (24) and in the present research a DNA oxidative damage model was established by applying different concentrations of $\mathrm{H}_{2} \mathrm{O}_{2}(0.05,0.1$ and $0.2 \mathrm{mM} / \mathrm{l})$. COL2 expression was used to monitor the degeneration of NP cells, following a previously described protocol (25). The expression of COL2 decreased as increasing concentrations of $\mathrm{H}_{2} \mathrm{O}_{2}$ were used, whereas the expression of TSHZ3 increased in an $\mathrm{H}_{2} \mathrm{O}_{2}$ concentration-dependent manner (Fig. 3A). The expression of COL2 was significantly decreased in all groups compared with the control and the expression of TSHZ3 was significantly increased in all groups compared with the control $(\mathrm{P}<0.01)$. This indicates that TSHZ3 is associated with DNA damage and degeneration in NP cells. The expression of miR-125b-1-3p also decreased in an $\mathrm{H}_{2} \mathrm{O}_{2}$ concentration-dependent manner and was significantly decreased in all groups compared with the control ( $\mathrm{P}<0.01$; Fig. 3B).

To elucidate the association between TSHZ3 and miR-125b-1-3p, TSHZ3 3'UTRs containing the wild type or

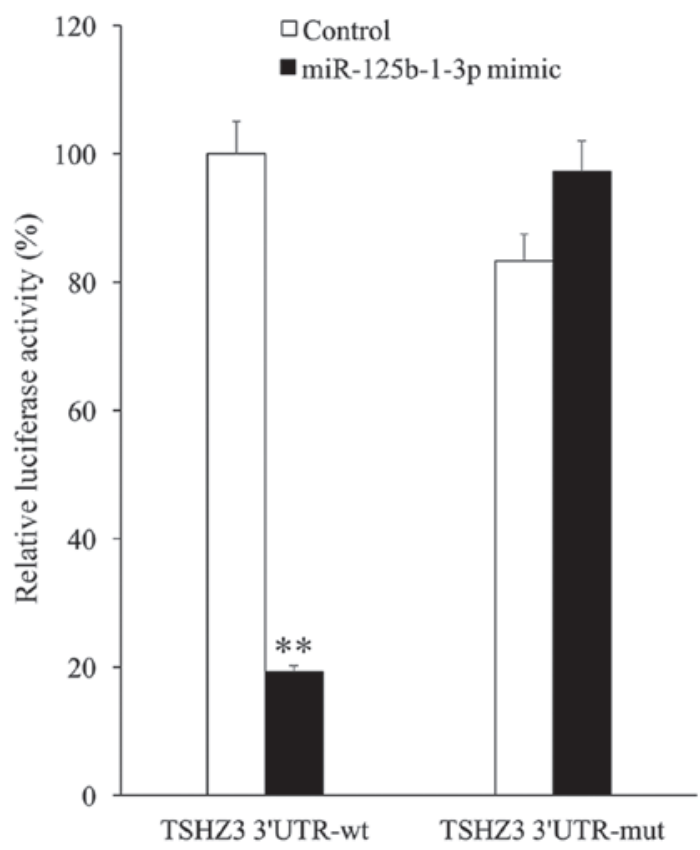

Figure 4. Luciferase reporter assay. Relative luciferase activity of wt or mut TSHZ3 3'UTR in 293T cells following co-transfection with normal control or miR-125b-1-3p mimic. ${ }^{* *} \mathrm{P}<0.01$ vs. control. UTR, untranslated region; miR, microRNA; mut, mutant; wt, wild-type.

mutant potential target site of miR-125b-1-3p were constructed and co-transfected with the miR-125b-1-3p mimic into $293 \mathrm{~T}$ cells. The results of the luciferase reporter assay demonstrated that the miR-125b-1-3p mimic significantly decreased the 

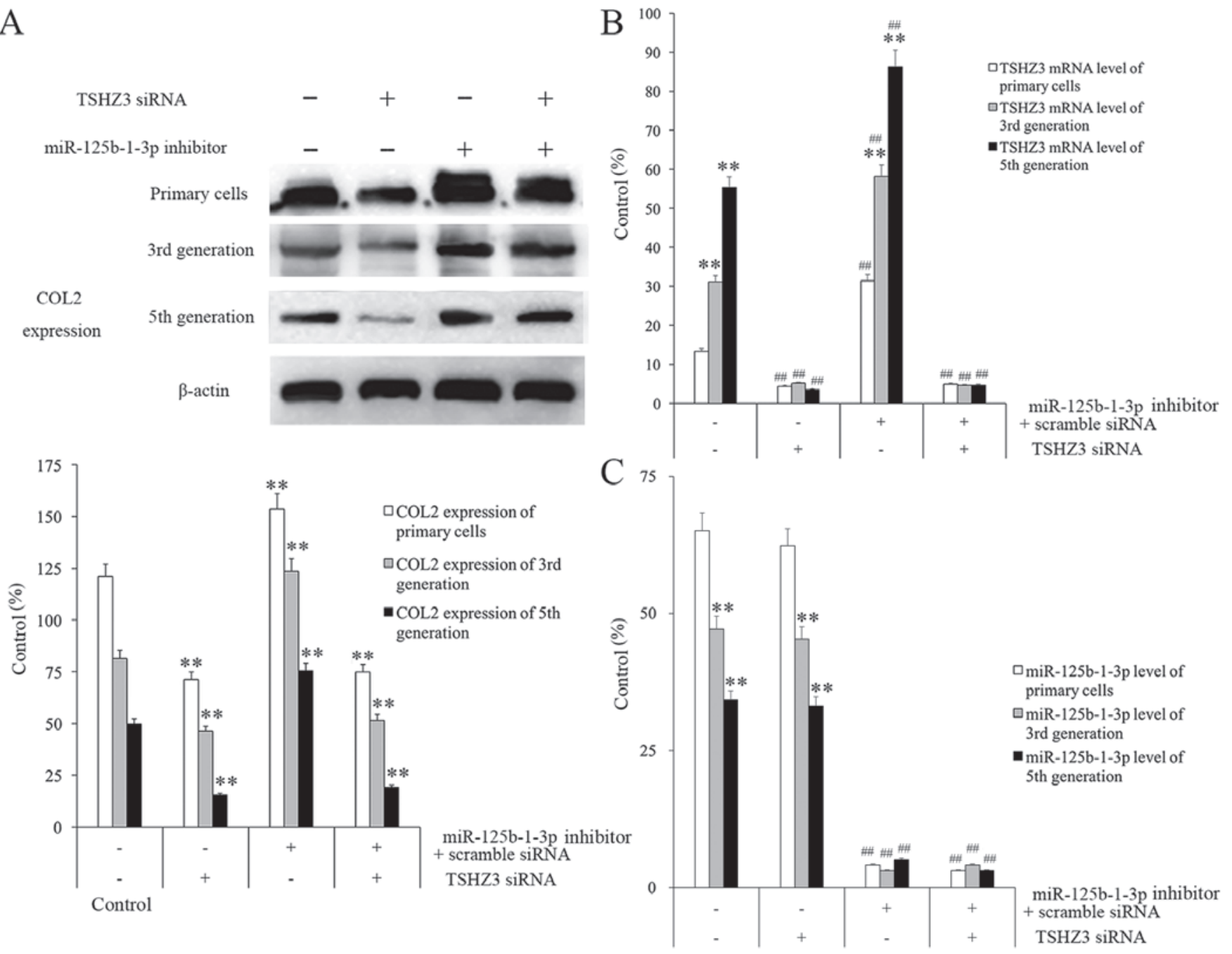

Figure 5. The effect of transfection with miR-125b-1-3p inhibitor and TSHZ3 siRNA on NP cells. TSHZ3 siRNA alone or combined with miR-125b-1-3p inhibitor was administered to NP cells and the expression of (A) COL2, (B) TSHZ3 and (C) miR-125b-1-3p was measured from different generations of NP cells. ${ }^{* *} \mathrm{P}<0.01$ vs. control cells among the generations. ${ }^{\# \#} \mathrm{P}<0.01$ vs. the control cells (inhibitor- and TSHZ3 siRNA-) among the treated groups in B and C. miR, microRNA. NP, nucleus pulposus; TSHZ3, Teashirt zinc finger homeobox 3; miR, microRNA; COL2, collagenase type II; siRNA, small interfering RNA.

luciferase activity of wild type TSHZ3 3'UTR compared with the control $(\mathrm{P}<0.01)$, whereas the luciferase activity of the mutant TSHZ3 3'UTR was unaffected by the miR-125b-1-3p mimic (Fig. 4).

NP cells were treated with different combinations of TSHZ3 siRNA and miR-125b-1-3p inhibitor and the results demonstrated that, although COL2 expression decreased in all of the groups in a passage-dependent manner, the overall expression levels at each passage differed between each treatment group (Fig. 5A). The group treated with TSHZ3 siRNA (alone or in combination with miR-125b-1-3p inhibitor) exhibited the lowest expression level of COL2 in each generation among all of the groups, whereas the group treated with the miR-125b-1-3p inhibitor alone exhibited the highest COL2 expression in every generation among all groups (Fig. 5A).

It was observed that NP cells treated with $60 \mathrm{nmol} / 1$ miR-125b-1-3p inhibitor for $24 \mathrm{~h}$ had the highest TSHZ3 mRNA levels and NP cells treated with only TSHZ3 siRNA had the highest miR-125b-1-3p mRNA levels compared to negatively treated cells in each group (Fig. 5B and C). It was clear that the expression of TSHZ3 in the miR-125b-1-3p inhibiting group increased significantly compared with the miR-125b-1-3p inhibitor treated group ( $\mathrm{P}<0.01$; Fig. 5B). These results indicate that the expression of TSHZ3 in normal NP cells may be an important factor protecting them against degeneration and that miR-125b-1-3p inhibits its expression in normal circumstances.

The expression of the cell cycle associated proteins (cyclin D1 associated with $\mathrm{G}_{1}$ phase and cyclin B1 associated with $G_{2} / M$ phase) was investigated and the results revealed that in the TSHZ3 siRNA treatment group, the expression of cyclins D1 and B1 were significantly downregulated compared with the control group (Fig. 6), which may induce $G_{1}$ and $G_{2} / M$ phase arrest and thus inhibit cell proliferation. By contrast, the expression of cyclins D1 and B1 were significantly increased in the miR-125b-1-3p treatment group compared with the control (Fig. 6).

\section{Discussion}

Degeneration of the intervertebral disc occurs due to morphological and histological changes to the intervertebral discs, as well as changes in the molecular biology of the NP, which are 
induced by internal and external factors (26). The proliferation and apoptosis of NP cells and the abnormal metabolism of the extracellular matrix components are key causes of intervertebral disk degeneration (27). The regeneration of normal NP cells is closely associated with their proliferation ability and maintenance of the extracellular matrix (28-31). Therefore, maintaining NP cell activity and slowing down the degeneration progress may be a novel method of preventing and treating degenerative diseases affecting the intervertebral discs.

Previous studies have demonstrated that certain cytokines may activate degeneration by inducing apoptosis, including by activating the tumor necrosis factor-associated apoptosis inducing-ligand that belongs to the TNK superfamily (3,4,32-34). In addition, certain cytokines promote the proliferation and inhibit the degeneration of NP cells, including insulin-like growth factor and thymosin $\beta-4$ (35-37).

The primary function of the extracellular matrix of the NP cells is to provide support and nutrients, whereas a decrease in the amount of extracellular matrix increases the susceptibility of NP cells to degeneration (5). Cytokines involved in the generation and degradation of the extracellular matrix include tumor necrosis factor ligand superfamily member, 12 transforming growth factor- $\beta 1$, matrix metalloproteinase and $\beta$-catenin (38-40).

COL2 is widely expressed in the extracellular matrix of NP cells. It provides the fibrous scaffold to the cell and therefore greatly influences the structure and function of NP cells (41). It has been previously reported that COL2 expression is decreased in degenerative NP cells and this may be used as an index to evaluate the proliferation capability and activity of NP cells (42). The results of the present study demonstrate that, following treatment with different concentrations of $\mathrm{H}_{2} \mathrm{O}_{2}$ for a specified period of time, the expression of COL2 decreases significantly indicating that degeneration is occurring.

When the NP cells were cultured in vitro to the third generation, degeneration was clear and mainly characterized by slow growth. In the present study, the expression of COL2 in the NP cells decreased in a passage-dependent manner, whereas the expression of TSHZ3 increased in a passage-dependent manner. This indicates that during cellular senescence, TSHZ3 may be a protective factor against degeneration.

The expression of miR-125b-1-3p exhibited no significant changes in third and fifth generation cells compared with the primary cells. It has been reported that miR-125b-1-3p acts as a tumor suppressor or an oncogene (14) and has diverse functions, including on cell development, differentiation, proliferation and apoptosis $(12,13)$. It has been demonstrated that miR-125b-1-3p is downregulated in malignancies originating in the ovary, bladder and breast but is upregulated in leukemia, prostate cancer and glioma (15). Additionally, the results of the luciferase reporter assay demonstrated that TSHZ3 was a direct target of miR-125b-1-3p.

NP cells were treated with $\mathrm{H}_{2} \mathrm{O}_{2}$ to stimulate DNA damage, as previously documented by Zhou et al (24). Following treatment with increasing concentrations of $\mathrm{H}_{2} \mathrm{O}_{2}$, the expression of COL2 significantly decreased and the expression of TSHZ3 was significantly increased compared with the control groups. Therefore, it may be hypothesized that TSHZ3 also serves a role in DNA repair.
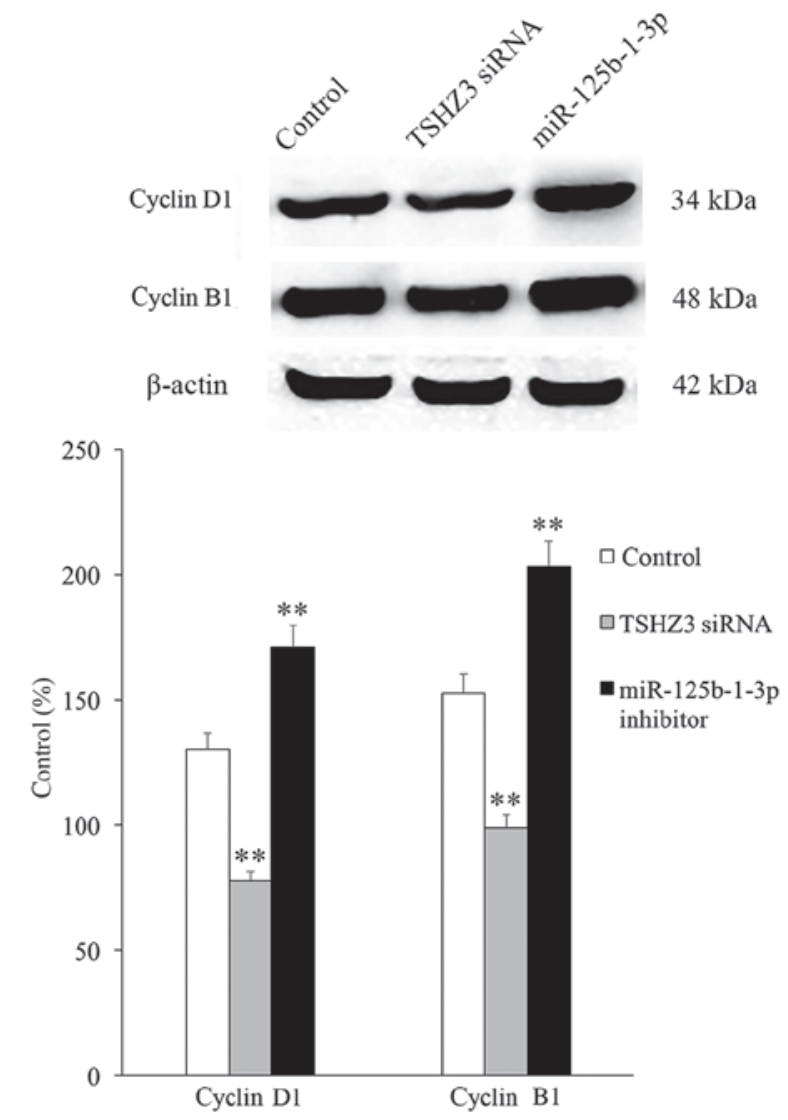

Figure 6. Expression of cyclins B1 and D1. TSHZ3 siRNA and miR-125b-1-3p were administered to NP cells alone or in combination, and the expression of cyclins D1 and B1 was measured by western blot analysis. ${ }^{* *} \mathrm{P}<0.01$ vs. the control cells. NP, nucleus pulposus; TSHZ3, Teashirt zinc finger homeobox 3; miR, microRNA; siRNA, small interfering RNA.

TSHZ3 siRNA and the miR-125b-1-3p inhibitor were administered alone or in combination to further investigate the association between miR-125b-1-3p, TSHZ3 and NP cell degeneration.

The expression of cell cycle associated proteins in NP cells was determined by western blot analysis following TSHZ3 silencing. The results revealed that the expression of cyclin D1 associated with the $\mathrm{G}_{1}$ phase and cyclin B1 associated with the $\mathrm{G}_{2} / \mathrm{M}$ phase of the cell cycle were significantly decreased, indicating that the inhibition of TSHZ3 may induce $\mathrm{G}_{1}$ and $\mathrm{G}_{2} / \mathrm{M}$ phase arrest, thus blocking the proliferation of NP cells.

In conclusion, the results of the present study demonstrate that TSHZ3, which is one of the target genes of miR-125b-1-3p, may serve a protective role in the degeneration and proliferation of NP cells in rats. This provides a novel molecular mechanism by which to study and more effectively understand intervertebral disc degeneration. However, further studies are required to elucidate its underlying mechanisms of action more comprehensively.

\section{Acknowledgements}

The present study was supported by the National Natural Science Foundation of China (grant no. 81472044) and the Shenyang Science and Technology Program-Population and Health Special (grant no. 17-230-9-04). 


\section{References}

1. Millward-Sadler SJ, Costello PW, Freemont AJ and Hoyland JA Regulation of catabolic gene expression in normal and degenerate human intervertebral disc cells: Implications for the pathogenesis of intervertebral disc degeneration. Arthritis Res Ther 11: R65, 2009.

2. Maniadakis $\mathrm{N}$ and Gray A: The economic burden of back pain in the UK. Pain 84: 95-103, 2000.

3. Takada T, Nishida K, Doita M and Kurosaka M: Fas ligand exists on intervertebral disc cells: A potential molecular mechanism for immune privilege of the disc. Spine (Phila Pa 1976) 27 1526-1530, 2002.

4. Wiley SR, Schooley K, Smolak PJ, Din WS, Huang CP, Nicholl JK, Sutherland GR, Smith TD, Rauch C, Smith CA, et al: Identification and characterization of a new member of the TNF family that induces apoptosis. Immunity 3: 673-682, 1995.

5. Bachmeier BE, Nerlich A, Mittermaier N, Weiler C, Lumenta C, Wuertz K and Boos N: Matrix metalloproteinase expression levels suggest distinct enzyme roles during lumbar disc herniation and degeneration. Eur Spine J 18: 1573-1586, 2009.

6. Wilkie R and Pransky G: Improving work participation for adults with musculoskeletal conditions. Best Pract Res Clin Rheumatol 26: 733-742, 2012.

7. Freemont AJ, Watkins A, Le Maitre C, Baird P, Jeziorska M, Knight MT, Ross ER, O'Brien JP and Hoyland JA: Nerve growth factor expression and innervation of the painful intervertebral disc. J Pathol 197: 286-292, 2002.

8. Roberts S, Evans EH, Kletsas D, Jaffray DC and Eisenstein SM Senescence in human intervertebral discs. Eur Spine J 15 (Suppl 3): S312-S316, 2006.

9. Kulasingam V and Diamandis EP: Strategies for discovering novel cancer biomarkers through utilization of emerging technologies. Nat Clin Pract Oncol 5: 588-599, 2008.

10. Liu J, Keisling MP, Samkari A, Halligan G, Pascasio JM and Katsetos CD: Malignant glioma with primitive neuroectodermal tumor-like component (MG-PNET): Novel microarray findings in a pediatric patient. Clin Neuropathol 35: 353-367, 2016.

11. Decock A, Ongenaert M, Van Criekinge W, Speleman F and Vandesompele J: DNA methylation profiling of primary neuroblastoma tumors using methyl-CpG-binding domain sequencing. Sci Data 3: 160004, 2016

12. Inui M, Martello $G$ and Piccolo S: MicroRNA control of signal transduction. Nat Rev Mol Cell Biol 11: 252-263, 2010.

13. Li W, Xie L, He X, Li J, Tu K, Wei L, Wu J, Guo Y, Ma X, Zhang $\mathrm{P}$, et al: Diagnostic and prognostic implications of microRNAs in human hepatocellular carcinoma. Int J Cancer 123: 1616-1622, 2008

14. Lee YS and Dutta A: MicroRNAs in cancer. Annu Rev Pathol 4: 199-227, 2009.

15. Gong J, Zhang JP, Li B, Zeng C, You K, Chen MX, Yuan Y and Zhuang SM: MicroRNA-125b promotes apoptosis by regulating the expression of Mcl-1, Bcl-w and IL-6R. Oncogene 32: 3071-3079, 2013

16. McGinnis W, Levine MS, Hafen E, Kuroiwa A and Gehring WJ: A conserved DNA sequence in homoeotic genes of the Drosophila Antennapedia and bithorax complexes. Nature 308: 428-433, 1984

17. Scott MP and Weiner AJ: Structural relationships among genes that control development: Sequence homology between the Antennapedia, Ultrabithorax, and fushi tarazu loci of Drosophila. Proc Natl Acad Sci USA 81: 4115-4119, 1984.

18. Macdonald PM and Struhl G: A molecular gradient in early Drosophila embryos and its role in specifying the body pattern. Nature 324: 537-545, 1986

19. Caubit X, Gubellini P, Andrieux J, Roubertoux PL, Metwaly M, Jacq B, Fatmi A, Had-Aissouni L, Kwan KY, Salin P, et al: TSHZ3 deletion causes an autism syndrome and defects in cortical projection neurons. Nat Genet 48: 1359-1369, 2016.

20. Faralli H, Martin E, Coré N, Liu QC, Filippi P, Dilworth FJ, Caubit X and Fasano L: Teashirt-3, a novel regulator of muscle differentiation, associates with BRG1-associated factor 57 (BAF57) to inhibit myogenin gene expression. J Biol Chem 286: 23498-23510, 2011.

21. Liu X, Che L, Xie YK, Hu QJ, Ma CJ, Pei YJ, Wu ZG, Liu ZH, Fan LY and Wang HQ: Noncoding RNAs in human intervertebral disc degeneration: An integrated microarray study. Genom Data 5: 80-81, 2015 .
22. Liang B, Li C and Zhao J: Identification of key pathways and genes in colorectal cancer using bioinformatics analysis. Med Oncol 33: 111, 2016

23. Livak KJ and Schmittgen TD: Analysis of relative gene expression data using real-time quantitative PCR and the 2(-Delta Delta C(T)) method. Methods 25: 402-408, 2001.

24. Zhou X, Zhang HL, Gu GF, Ding Y, Jia JB, Fu QS and He SS: Investigation of the relationship between chromobox homolog 8 and nucleus pulposus cells degeneration in rat intervertebral disc. In Vitro Cell Dev Biol Anim 49: 279-286, 2013.

25. Kim KS, Yoon ST, Park JS, Li J, Park MS and Hutton WC: Inhibition of proteoglycan and type II collagen synthesis of disc nucleus cells by nicotine. J Neurosurg 99 (3 Suppl): S291-S297, 2003.

26. Cao Y, Liao S, Zeng H, Ni S, Tintani F, Hao Y, Wang L, Wu T, $\mathrm{Lu} \mathrm{H}$, Duan C and Hu J: 3D characterization of morphological changes in the intervertebral disc and endplate during aging: A propagation phase contrast synchrotron micro-tomography study. Sci Rep 7: 43094, 2017.

27. Wang J, Pan H, Li X, Zhang K, Li Z, Wang H, Zheng Z and Liu H: Hypoxia suppresses serum deprivation-induced degradation of the nucleus pulposus cell extracellular matrix through the JNK and NF- $\kappa$ B pathways. J Orthop Res 35: 2059-2066, 2017.

28. Luoma K, Riihimäki H, Luukkonen R, Raininko R, Viikari-Juntura $E$ and Lamminen A: Low back pain in relation to lumbar disc degeneration. Spine (Phila Pa 1976) 25: 487-492, 2000.

29. Sobajima S, Shimer AL, Chadderdan RC, Kompel JF, Kim JS, Gilbertson LG and Kang JD: Quantitative analysis of gene expression in a rabbit model of intervertebral disc degeneration by real-time polymerase chain reaction. Spine J 5: 14-23, 2005.

30. Jiricny J: The multifaceted mismatch-repair system. Nat Rev Mol Cell Biol 7: 335-346, 2006.

31. Urban JP and Roberts S: Degeneration of the intervertebral disc. Arthritis Res Ther 5: 120-130, 2003

32. Dai X, Zhang J, Arfuso F, Chinnathambi A, Zayed ME, Alharbi SA, Kumar AP, Ahn KS and Sethi G: Targeting TNF-related apoptosis-inducing ligand (TRAIL) receptor by natural products as a potential therapeutic approach for cancer therapy. Exp Biol Med (Maywood) 240: 760-773, 2015.

33. Heyde CE, Tschoeke SK, Hellmuth M, Hostmann A, Ertel W and Oberholzer A: Trauma induces apoptosis in human thoracolumbar intervertebral discs. BMC Clin Pathol 6: 5, 2006.

34. Buckwalter JA: Aging and degeneration of the human intervertebral disc. Spine (Phila Pa 1976) 20: 1307-1314, 1995.

35. Pasold J, Zander K, Heskamp B, Grüttner C, Lüthen F, Tischer T, Jonitz-Heincke A and Bader R: Positive impact of IGF-1-coupled nanoparticles on the differentiation potential of human chondrocytes cultured on collagen scaffolds. Int J Nanomedicine 10: 1131-1143, 2015.

36. Niu M and Nachmias VT: Increased resistance to apoptosis in cells overexpressing thymosin beta four: A role for focal adhesion kinase pp125FAK. Cell Adhes Commun 7: 311-320, 2000.

37. Tapp H, Deepe R, Ingram JA, Yarmola EG, Bubb MR, Hanley EN Jr and Gruber HE: Exogenous thymosin beta4 prevents apoptosis in human intervertebral annulus cells in vitro. Biotech Histochem 84: 287-294, 2009.

38. Huh H, Lee YJ, Kim JH, Kong MH, Song KY and Choi G: The effects of TWEAK, Fn14, and TGF-beta1 on degeneration of human intervertebral disc. J Korean Neurosurg Soc 47: 30-35, 2010.

39. Reno F, Sabbatini M, Stella M, Magliacani G and Cannas M: Effect of in vitro mechanical compression on Epilysin (matrix metalloproteinase-28) expression in hypertrophic scars. Wound Repair Regen 13: 255-261, 2005.

40. Gruber HE, Ingram JA, Hoelscher GL, Zinchenko N, Norton HJ and Hanley EN Jr: Matrix metalloproteinase 28, a novel matrix metalloproteinase, is constitutively expressed in human intervertebral disc tissue and is present in matrix of more degenerated discs. Arthritis Res Ther 11: R184, 2009.

41. Yokoyama K, Hiyama A, Arai F, Nukaga T, Sakai D and Mochida J: C-Fos regulation by the MAPK and PKC pathways in intervertebral disc cells. PLoS One 8: e73210, 2013.

42. Lohmander LS, Neame PJ and Sandy JD: The structure of aggrecan fragments in human synovial fluid. Evidence that aggrecanase mediates cartilage degradation in inflammatory joint disease, joint injury, and osteoarthritis. Arthritis Rheum 36: $1214-1222,1993$ 